\title{
DESAIN BUKU AJAR TARI OREK-OREK NGAWI DALAM BENTUK POP UP
}

\author{
Martha Tisna Ginanjar Putri \\ Program Studi Desain Komunikasi Visual, \\ Fakultas Bahasa dan Seni, Universitas Indraprasta PGRI
}

\begin{abstract}
Abstrak. Tari Orek-Orek merupakan tarian khas Jawa Timur dari Kabupaten Ngawi yang sering ditampilkan pada acara-acara besar di Ngawi. Tari Orek-Orek Ngawi mulai dikenalkan pada anakanak sekolah terutama sekolah dasar di ekstrakulikuler dan di sanggar. Selama ini anak-anak kurang memahai makna dari Tari Orek-Orek karena kurangnya referensi buku tenetang Tari OrekOrek. Tujuan penelitian ini adalah untuk mengembangkan buku ajar Tari Orek-Orek Ngawi yang semula dalam bentuk buku ketikan mesin ketik manual menjadi buku yang lebih menarik dalam bentuk pop up. Cara mendesain buku Tari Orek-Orek Ngawi menggunakan model pengembangan yang mengacu pada Four-D oleh Thiagarajan yang dimodifikasi menjadi Three-D. Model ini terdiri dari 3 tahap pengembangan, yaitu Define, Design dan Develop (pendefinisian, perancangan, dan pengembangan). Dalam proses perancangan buku ajar beracuan pada Badan Standar Nasional Pendidikan (BSNP) 2007 tentang Kelayakan Kegrafikaan. Buku ajar Tari Orek-Orek Ngawi dalam bentuk pop up merupakan buku yang dibuat untuk mengenalkan tari khas Jawa Timur, yaitu Tari Orek-Orek Ngawi. Buku ini ditujukan untuk memberikan materi kepada anak Sekolah Dasar di Kabupaten Ngawi.
\end{abstract}

Kata Kunci: Desain, buku ajar, tari Orek-Orek, Kelayakan kegrafikaan

\begin{abstract}
The Orek-Orek dance is a traditional East Javanese Dance from Ngawi City which is often performed at major events in Ngawi. The Orek-Orek Ngawi dance began to be introduced to school children, especially elementary schools in the extracurricular and in the studio. During this time the children lack understanding the meaning of the Orek-Orek dance and the lack of reference books about the Orek-Orek dance. The purpose of this study was to develop a textbook on dance for Ngawi orek, which was originally in the form of a typewriter typing book into a more interesting book in the form of pop ups. The way to design the dance book Ngawi Orek-Orek uses a development model that refers to Four-D by Thiagarajan, which was modified into Three-D. This model consists of 3 stages of development, namely Define, Design and Develop. In the process of designing textbooks referring to the 2007 National Education Standards Agency (BSNP) on the Eligibility of Graphics. Ngawi's Orek-Orek dance textbook in pop-up form is a book created to introduce East Javanese dance, the Orek-Orek Ngawi dance. This book is intended to provide material to elementary school children in Ngawi City.
\end{abstract}

Keyword: Design, Textbook, Orek-Orek Dance, Graphic

Correspondence author: Matha Tisna Ginanjar Putri, Jakarta, Indonesia 


\section{Pendahuluan}

Kabupaten Ngawi memiliki banyak kesenian salah satunya Tari Orek-Orek Ngawi. Pada saat ini Tari Orek-Orek Ngawi digencarkan untuk dipopulerkan pada event besar. Selama ini masyarakat Ngawi hanya melihat Tari Orek-Orek Ngawi dari segi tampilan, tanpa mengapresiasi lebih dalam mengenai makna tari orek-orek tersebut. Berdasarkan buku yang disusun oleh Depdikbud Provinsi Jawa Timur melalui Proyek Pembinaan Kesenian Jawa Timur tahun anggaran 1993 /1994 dengan judul Tari Orek_Orek Ngawi menjelaskan bahwa Tari Orek-Orek pada sejarahnya merupakan suatu seni pertunjukan drama yang menyerupai ketoprak. Lakon yang dibawakan oleh kesenian ini sering kali mengambil petikkan dari sejarah-sejarah kerajaan yang ada di daerah Jawa. Pada perkembangannya, kesenian ini mendapat sambuatan pula sebagai kesenian tontonan, karena dengan berkeliling kampung, dari rumah kerumah atau diadakan ditengah-tengah perempatan kampung. Semua pemain seni Orek-Orek ini adalah laki-laki. Meskipun peran dalam lakon ada yang perempuan, namun tetap laki-laki yang memainkan. Alat musik yang digunakan sangat sederhana yaitu lesung.

Gending Orek-Orek tetap hidup karena masih digunakan pada kesenian Tayuban. Iringan kesenian Orek-Orek juga dinamai gending Orek-Orek dengan laras Slendro. Pada tahun 1981 Pemerintah Kabupaten Ngawi berusaha untuk mengangkat kembali nama Orek-Orek ini menjadi ikon kabupaetn Ngawi (Tim Proyek Pembinaan Jawa Timur 12-15).

Menurut buku yang disusun Tim Proyek Pembinaan Jawa Timur (16-19) dan hasil wawancara dari salah satu pencipta dan pengembang tari Orek-Orek di Kabupaten Ngawi, Pada tahun 1981 Pemerintah Kabupaten Ngawi berusaha untuk mengangkat kembali nama OrekOrek ini dipermukaan kebudayaan Nasional. Ibu Sri Widajati merupakan salah satu pencipta dan pengembang tari Orek-Orek. Tari Orek-Orek Ngawi merupakan tari pergaulan. Tari ini dimasukkan pada tari pergaulan dikarenakan dengan tujuan untuk mempermudah penyebaran kesenian tari Orek-Orek ini. Meskipun merupakan tari pergaulan, namun tari ini tidak memiliki unsur arti atau makna yang mengarah pada hubungan intim laki-laki dan perempuan. Maksud tari pergaulan di sini merupakan tarian yang dapat ditarikan secara berpasangan. Arti dan makna dari setiap gerakan mengacu pada sejarah tari Orek-Orek ini sendiri, yaitu muda mudi yang bergembira dalam menyelesaikan pekerjaan membangun bendungan dan jembatan secara gotong royong dan penuh semangat.

Tari Orek-Orek Ngawi memiliki nilai budaya untuk dikaji dan diimplementasikan dalam kehidupan sehari-hari terutama penanaman pendidikan nilai budaya kepada generasi muda. Sebagai karya seni tari tradisional Ngawi, Tari Orek-Orek Ngawi memiliki bentuk rupa dan unsurunsur rupa yang beragam yang dapat dimanfaatkan sebagai media apresiasi khususnya dalam pembelajaran seni budaya. Dikaji dari perwujudan estetika sebagai hasil seni baik memiliki bentuk ragam gerakan, ragam hias, dan karakter.

Di Kabupaten Ngawi, kesadaran masyarakan dalam pengembangan seni budaya masih sangat lemah. Hal ini terbukti kurang pahamnya masyarakat terhadap budaya lokal. Sekolah di Kabupaten Ngawi, terutama jenjang Sekolah Dasar masih kurang diperkenalkan dengan budaya lokal Ngawi, salah satunya adalah Tari Orek-Orek Ngawi. Masih jarang sekolah yang mengadakan ekstrakulikuler tarian lokal. Di Kabupaten Ngawi hanya tersisa satu sanggar seni tari yang masih berjuang untuk tetap berkembang. Sanggar Seni Sri Budaya yang di pimpin oleh Ibu Sri Widajati tersebut telah melahirkan ribuan penari di Kabupaten Ngawi dari berbagai tingkatan usia dan pendidikan. Selama ini sistem pembelajaran di Sekolah atau Sanggar tidak mengenalkan pembelajran apresiasi terhadap siswanya. Tidak ada pengenalan terhadap makna dan penjelasan lebih detail tentang tari-tari yang diajarkan, kususnya tari Orek-Orek. 
Kurangnya referensi untuk memahami lebih detail tentang tarian-tarian Ngawi, khususnya buku tentang tarian Orek-Orek Ngawi membuat pembelajaran apresiasi sangat jarang diajarkan di sekolah formal maupun non formal. Terdapat satu referensi buku tari OrekOrek namun merupakan buku cetakan lama. Buku tersebut dibuat pada tahun 1994. Pembelajaran di sekolah formal dan non formal dilakukan dengan proses otodidak dengan mengajarkan pembelajaran ekspresi saja.

Materi tari yang seharusnya diberikan di Sekolah ataupun Sanggar disesuaikan dengan kondisi dan kebutuhan siswa. Kebiasaan siswa memanfaatkan teknologi digital dalam aktivitas sehari-hari berdampak terhadap cara pandang mereka terhadap keberadaan seni tradisi yang dianggap kuno dan tidak menarik. Padahal jika kita melihat karakter siswa SD pada dasarnya memiliki rasa ingin tahu, tanggap terhadap permasalahan dan kompleksitasnya, dan minat untuk memahami fenomena secara bermakna (Muqodas 1).

Materi pembelajaran apresiasi seni tari yang disajikan melalui ceramah dikelas dengan menggunakan benda/buku cenderung tidak disukai oleh siswa. Guru harus melakukan berbagai macam inovasi dalam menyiapkan bahan ajar, salah satunya dengan mengemas kebudayaan tradisional melalui pembelajaran yang menarik bagi siswa. Sebagai usaha untuk meningkatkan sikap apresiatif siswa sekolah formal atau non-formal tingkat Sekolah Dasar terhadap seni tari di Kabupaten Ngawi, kususnya tari Orek-Orek sebagai pembelajaran apreasiasi, penelitian ini akan menghasilkan produk buku ajar apresiasi dalam bentuk Pop Up. Hanifah menyatakan bahwa Salah satu media yang dapat digunakan untuk meningkatkankan kecerdasan verballinguistik anak adalah melalui Pop-Up book.

Buku pop up memiliki keunggulan visual dalam hal bentuk fisiknya yang menarik dan interaktif terhadap anak. Hal ini sejalan dengan Metode pembelajaran yang tepat utuk anak usia SD adalah metode pembelajaran konstruktifistik. Menurut teori Konstruktufitif Jean Piaget dalam (Nurmawati et al. 2) Sekolah Dasar yang usianya 7-12 tahun berada pada tahap operasi kongkret. Cara berpikir siswa masih pada bantuan benda-benda kongrit. Dalam artikel Pendidikan Dasar yang berjudul "Peningkatan Kemampuan Membaca Dan Menulis Permulaan Melalui Pembelajaran Konstruktivisme" (Sukartiningsih 98) mengemukakan bahwa dengan pembelajaran konstruktivisme, interaksi yang terjadi antara guru dan siswa dapat lebih maksismal. Elvinawati (24) menjelaskan bahwa konstruktivesme adalah aliran filsafat pengetahuan yang menekankan bahwa pengetahuan kita merupakan hasil konstrksi kita sendiri. Pembelajaran konstruktivistik diharapkan murid dapat mengkonstruk atau membangun sendiri pengetahuannya melalui pengalaman-pengalaman yang didapat dari proses pembelajaran ataupun melalui guru sebagai fasilitator. Dengan demikian pop up bisa menjadi fasilitas pembelajaran yang menarik dan mudah dikonstruksikan pada ingaran anak SD dalam mengenal Tari Orek-Orek Ngawi

Desain buku pop dalam penelitian ini menggunakan prinsip kelayakan kegrafikaan yang diatur BSNP 2007 tentang buku ajar. Menurut Muslich (52), buku ajar berfungsi sebagai (1) sarana pengembangan bahan dan program kurikulum pendidikan; (2) sarana memperlancar tugas akademik guru; (3) sarana memperlancar ketercapaian tujuan pembelajaran dan (4) sarana pemerlancar efisiensi dan efektivitas kegiatan pembelajaran. Pengembangan desain buku menggukanan menggunakan teori Four-D yang disarankan oleh Thiagarajan dalam (Trianto 66) yang dimodifikasi menjadi Three-D. Model ini terdiri dari 3 tahap pengembangan, yaitu Define, Design dan Develop (pendefinisian, perancangan, dan pengembangan).

Melalui pengembangan buku ajar Tari Orek-Orek Ngawi, diharapkan dapat membantu siswa dalam mengenal, memahami, dan mengapresiasi karya Seni Tari Orek-Orek sebagai bagian dari seni Nusantara yang tumbuh dan berkembang di Kabupaten Ngawi. Selain itu pembelajaran 
apresiasi tersebut dapat membangun karakter anak yang diambil dari kekayaan budaya yang telah mereka pelajari.

\section{Metode Penelitian}

Pembuatan buku pop up ini berpedoman pada standar buku ajar dari BSNP 2007 agar memenuhi kualitas dan tujuan. Standar tersebut meliputi kelayaan isi, penyajian, kebahasaan dan kegrafikaan. Bagan kelayakan BSNP 2007 mengenai Buku Ajar :

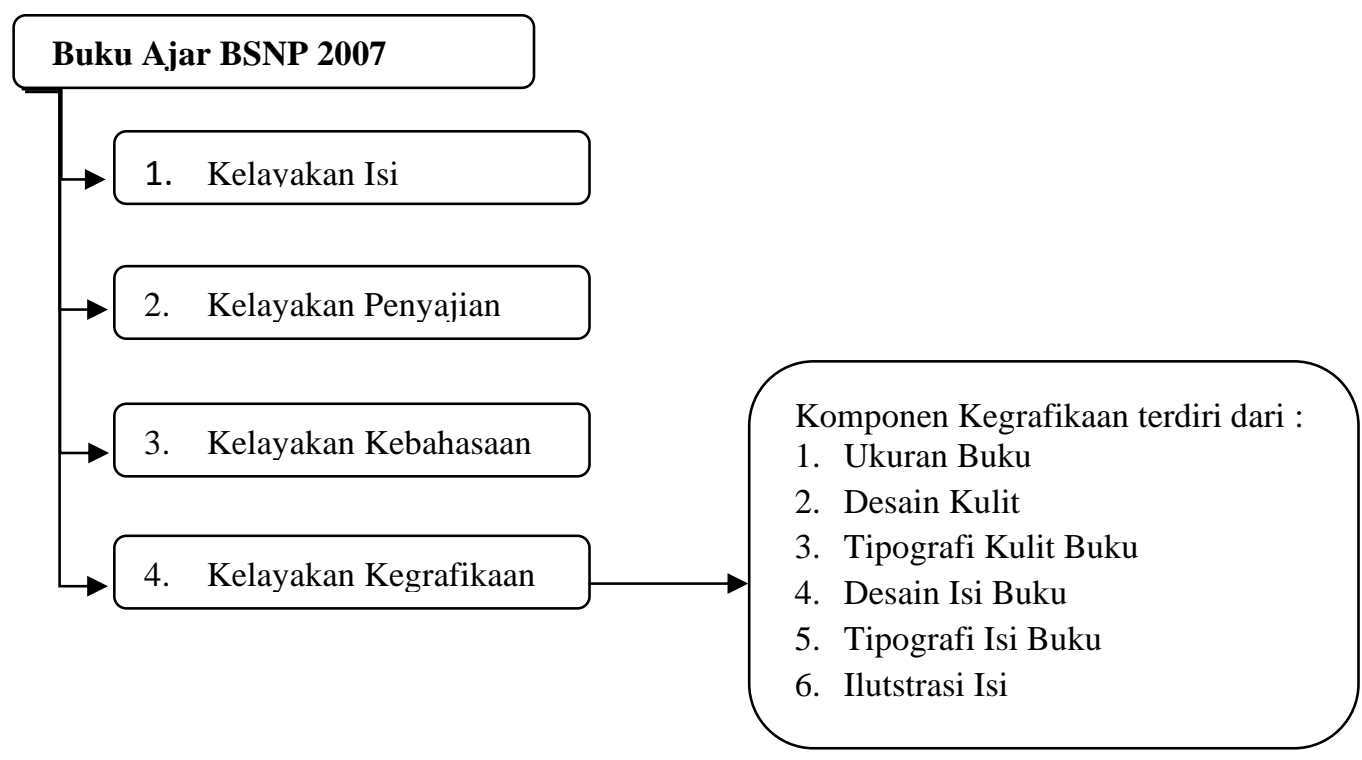

\section{Komponen Kegrafikaan Buku Ajar Menurut BSNP 2007}

Komponen kegrafikaan terdiri atas enam subkomponen, yaitu ukuran buku, desain kulit, tipografi kulit buku, desain isi buku, tipografi isi buku dan ilustrasi isi dengan perincian:

1. Ukuran buku mencakup (1) kesesuaian ukuran buku dengan standar iso A4 (2) kesesuaian ukuran dengan materi isi buku ;

2. Desain kulit buku mencakup (1) penampilan unsur terletak pada kulit muka, belakang dan punggung secara harmonis memiliki irama dan kesatuan serta konsisten., (2) menampilkan pusat pandang (center point)nyang baik, (3) komposisi dan ukuran tata letak (judul, pengarang, ilustrasi, logo, dll), proporsional, seimbang dan seirama dengan tataletak isi (sesuai pola), (4) warna unsur tataletak harmonis dan memperjelas fungsi, (5) menetapkan unsur tata letak konsisten dalam satu seri.

3. Tipografi kulit buku mencakup (1) huruf yang digunakan menarik dan mudah dibaca mencakup (a) ukuran huruf judul buku lebih dominan dan proposionaldibandingkan (ukuran buku, nama pengarang, dan penerbit), (b) Warna Judul buku kontras dengan warna latar belakang. (2) huruf yang sederhana atau komunikatif mencakup (a) tidak menggunakan terlalu banyak jenis huruf (b) tidak menggunakan huruf hias dan jenis huruf sesuai dengan huruf isi buku, (3) ilustrasi kulit buku mencerminkan isi buku mencakup (a) menggambarkan isi/materi ajar dan mengungkap karakter objek, (b) bentuk, warna, ukuran dan proporsi objek sesuai realita.

4. Desain isi buku mencakup (1) tataletak isi dan tataletak konsisten mencakup (a) penempatan unsur tataletak konsisten berdasarkan pola, (b) pemisahan antar paragraf jelas, (c) tidak ada 
widou atau orphan . (2) unsur tataletak harmonis mencakup (a) bidang cetak dan margin proporsional, (b) margin dua halaman yang proporsional, (c) spasi antar teks dan ilustrasi sesuai, (3) unsur tataletak lengkap mencakup (a) judul bab, sub judul bab dan angka halaman/filosofis, (b) ilustrasi dan keterangan gambar (caption); (4) tataletak mempercepat pemahaman mencakup (a) penempatan hiasan/ilustrasi sebagai latar belakang tidak mengganggu judul, teks, angka halaman, (b) penempatan judul, subjudul, ilustrasi dan keterangan gambar tidak mengganggu pemahaman.

5. Tipografi isi buku mencakup (1) tipografi sederhana mencakup (a) tidak menggunakan terlalu banyak jenis huruf, (b) tidak menggunakan jenis huruf hias atau dekoratif, (c) penggunaan fariasi huruf bold, italic, dan all capital. (2) tipografi mudah dibaca mencakup, (a) jenis huruf sesuai dengan materi isi, (b) lebar susunan teks antara 45-75 karakter (sekitar 5-11 kata), (c) spasi antar baris sususnan teks normal, (d) spasi antar huruf normal. (3) tipigrafi memudahkan pemahaman mencakup (a) jenjang/hierarki judul-judul jelas, konsisten dan proporsional, (b) tidak terdapat alur putih dalam susunan teks, (c) tanda potongan kata (hyphenation).

6. Ilustrasi isi mencakup (1) memperjelas dan mempermudah pemahaman terdiri atas (a) mampu mengungkap makna atau arti dari objek, (b) bentuk akurat dan proporsional sesuai dengan kenyataan; (2) ilustrasi isi menimbulkan daya tarik mencakup, (a) keseluruhan ilustrasi serasi, (b) goresan garis dan raster tegas dan jelas, (c) kreatif dan dinamis.

Teori pengembangan buku ajar ini menggunakan teori Four-D yang disarankan oleh Thiagarajan 1974 dalam (Trianto 66) yang dimodifikasi menjadi Three-D. Model ini terdiri dari 3 tahap pengembangan, yaitu Define, Design dan Develop (pendefinisian, perancangan, dan pengembangan).

Langkah-langkah pengembangan media pembelajaran, multimedia interaktif Tari OrekOrek Ngawi ini, mengacu pada model Four-D meliputi:

Tahap I Define (Pendefisian)

Merupakan tahap awal untuk memulai penelitian pengembangan dengan melakukan analisis yang meliputi, analisis awal konsep, analisis karakteristik pengguna, analisis tugas untuk mengukur kemampuan, dan perumusan buku ajar.

\section{Tahap I/ Design (Perancangan Desain)}

Pada tahap ini peneliti membuat pola yang disesuaikan dengan BSNP 2007, yaitu memperhatikan kelayakan isi, penyajian kebahasaan dan kegrafikaan. Dalam perancangan secara fisik buku yang paling terpenting adalah desain yang melalui kelayakan kegrafikaan. Buku Pop Up yang dibuat dalam tahap ini disebut Draf I. Selanjutnya adalah kegiatan validasi Draf I oleh tim Validator I. Tim ini adalah orang-orang yang ahli dibidang kegrafikaan. Yang dilihat dari kelayakan kegrafikaan adalah ukuran buku, desain kulit, tipografi kulit buku, desain isi buku, tipografi isi buku dan ilutstrasi isi.

\section{Tahap III Develop (Pengembangan)}

Merupakan tahap untuk mengetahui tingkat kelayakan Draf I. hasil penilaian, dimasukkan, dan saran dari tim validator I merupakan dasar untuk merevisi Draf I. kegiatan ini merupakan kegiatan Revisi I. Buku ajar yang telah direvisi, disampaikan kembali ke tim validator I sampai mendapat persetujuan. Media pembelajaran yang telah divalidasi, memiliki nilai layak bila interval presentase dalam kategori baik (Muslich). 
Penjabaran Proses desain Buku Ajar Tari Orek-Orek Ngawi dalam bentuk pop up
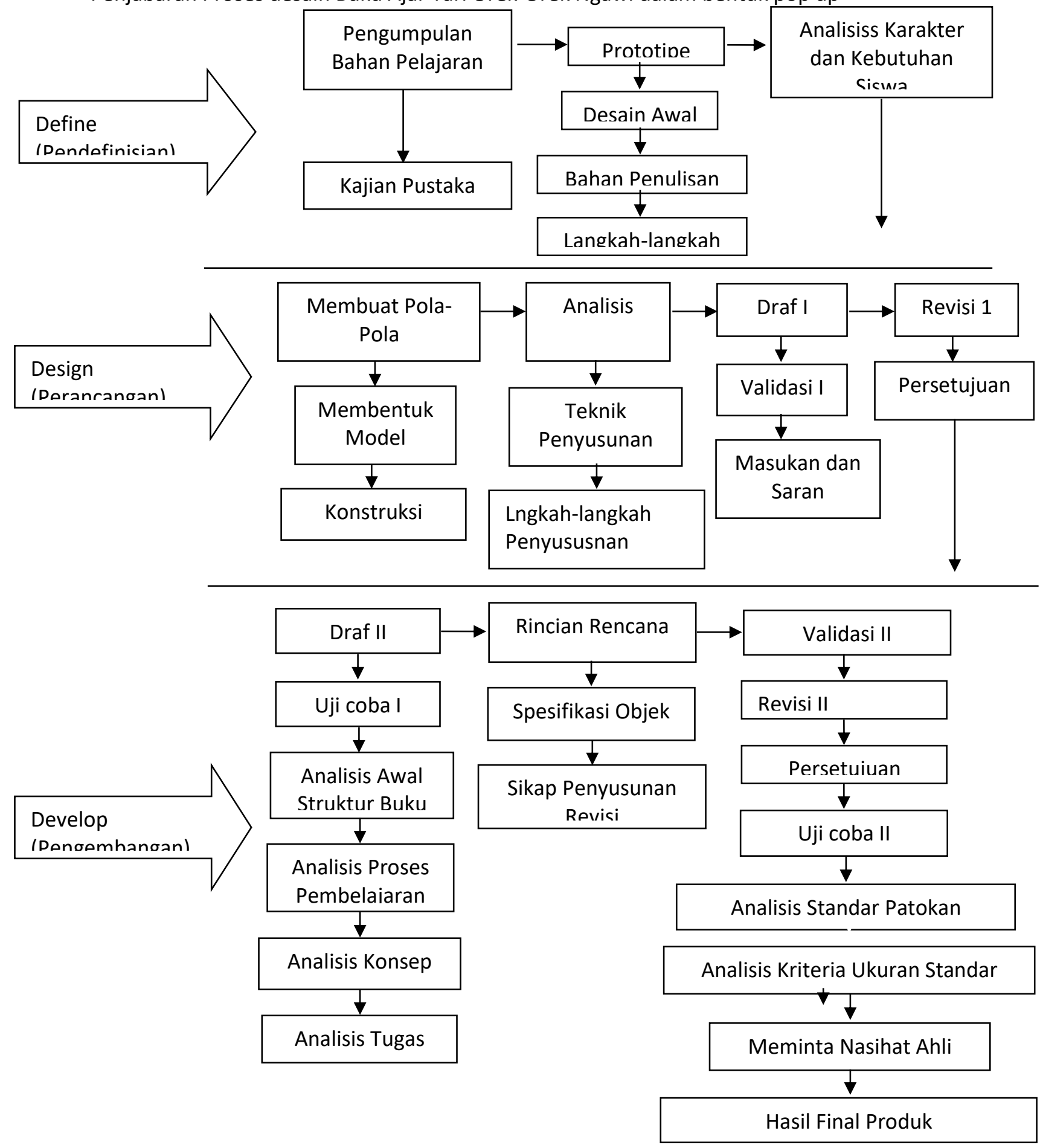

Alur Pengembangan Model 4D Sumber: Diadaptasi dari Thiagarajan dalam (rianto 66) yang dimodifikasi menjadi 3D

\section{Pembahasan}

Berikut ini adalah deskripsi proses desain buku pop up Tari Orek-Orek Ngawi degan standar BSNP atau badan Standarisasi Nasional Penddikan 2007 dari kelayakan kegrafikaan 
melalui metode three D yaitu Define, Design dan Develop (pendefinisian, perancangan, dan pengembangan).

\section{Tahap I Define (Pendefisian)}

Merupakan tahap awal untuk memulai penelitian pengembangan dengan melakukan analisis sebagai berikut:

1. Analisis awal untuk memberikan konsep dari permasalahan pentingnya dibuat buku Pop Up Tari Orek-Orek Ngawi karena kurangnya referensi buku Tari Orek-Orek Ngawi.

2. Analisis karakteristik pengguna buku yaitu anak sekolah dasar di ekstrakulikuler dan di sanggar tari. Karakteristik yang diketahui setelah diteliti disesuaikan dengan metode pembelajaran anak usia SD yaitu konstruktifistik. Buku pop up cocok digunakan karena dapat mengkonstruksikan memori anak dengan buku yang interaktif dan menarik.

3. Analisis tugas terhadap pengguna untuk mengetahui tingkat pemahaman siswa terhadap materi tari Orek-Orek sebelum menggunakan buku pop up.

4. Perumusan tujuan buku ajar (specifying Insruction objectives) merupakan rangkuman hasil dari analisis tugas untuk menentukan tujuan pembelajaran yanga dicapai dalam buku ajar yang dikembangkan. Tujuan dari buku ajar apresiasi seni Tari Orek-Orek Ngawi dengan memanfaatkan tampak rupa seni Tari Orek-Orek Ngawi sebagai objek apresiasi dengan isi materi Sejarah, Tata Rias, Kostum, Ragam Gerak, Alat Musik dan Tembang Pengiring

\section{Tahap II Design (Perancangan Design)}

Pada tahap ini peneliti membuat pola yang disesuaikan dengan BSNP 2007, yaitu memperhatikan kelayakan isi, penyajian kebahasaan dan kegrafikaan. Dalam perancangan secara fisik buku yang paling terpenting adalah desain yang melalui kelayakan kegrafikaan. Buku Pop Up yang dibuat dalam tahap ini disebut Draf I. Selanjutnya adalah kegiatan validasi Draf I oleh tim Validator I. Tim ini adalah orang-orang yang ahli dibidang kegrafikaan. Yang dilihat dari kelayakan kegrafikaan adalah:

1. Ukuran Buku

Buku Pop Up Tari Orek-Orek Ngawi dibuat dengan ukuran A4 sesuai dengan standar iso dan sudah ada kesesuaian dengan materi, mudah dilihat dengan jelas.

2. Desain kulit buku

Tampilan kulit buku Pop Up Tari rek-Orek Ngawi dari tampak depan, belakan dan samping sudah harmonis karena kekonsistenan warna yang dipakai. Unsur warna yang digunakan adalah hijau sebagai background dominan dengan variasi analogus kuning sebagai fariasi. Pink tua dan ungu sebagai kontras dari hijau menjadikan judul buku semakin terlihat jelas dan menarik. Terdapat point of interest atau center point dari gambar sepasang penari Orek-Orek dengan pakian khasnya. Komposisi Ukuran judul dominan besar dan seimbang dengan Gambar agar terlihat jelas dan menarik. Logo terletak di bawah dan lebih kecil dari gambar diberikan background kuning untuk logo dan nama instansi agar kontras dengan warna logo sehingga logo masih terlihat jelas. 


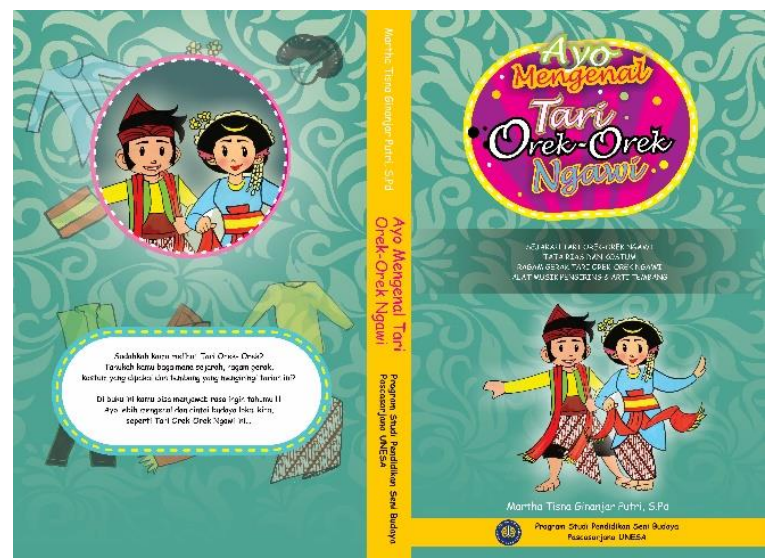

Gambar 1 tampilan kulit buku

3. Tipografi kulit buku

Huruf yang digunakan pada judul buku mnggunakan jenis huruf curlz mt agar berbeda dan mencolok dnegan tuliasan sekitar judul yang menggunakan jenis huruf comic sans MS. Jenis huruf ini sederhana namun tetap komunikatif. Warna tulisan juga kontras dengan background nya sehingga mudah dibaca dengan jelas.

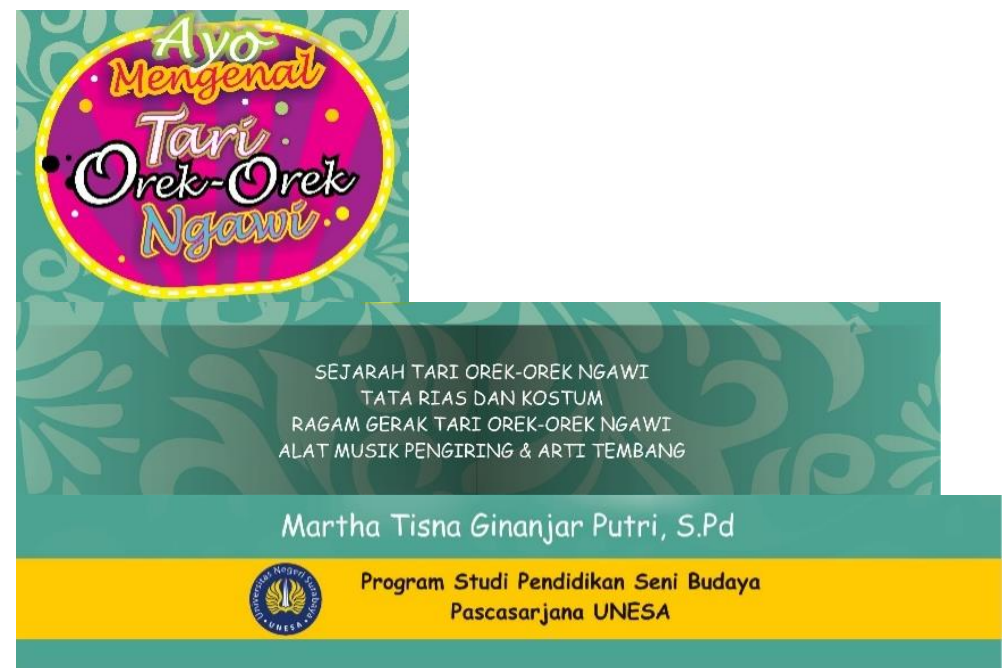

Gambar 2 Contoh tipografi sampul buku

4. Desain isi buku

Buku Pop Up ini terdapat 5 bab yaitu Sejarah, Tata Rias, Kostum, Ragam Gerak, Alat Musik dan Tembang Pengiring yang ditata secara konsisten dan sama. Urutan tata letak pada masng masing bab adalah sub judul bab, penjelasan sub bab, tujuan pembelajaran, isi materi, rangkuman dan soal latihan. Buku pop up terdapat pada isi materi, ilustrasi tidak mnggaggu penjelasan, jutrus ilustrasi yang berbentuk pop up bisa mendukung pejelasn materi tertulis. 


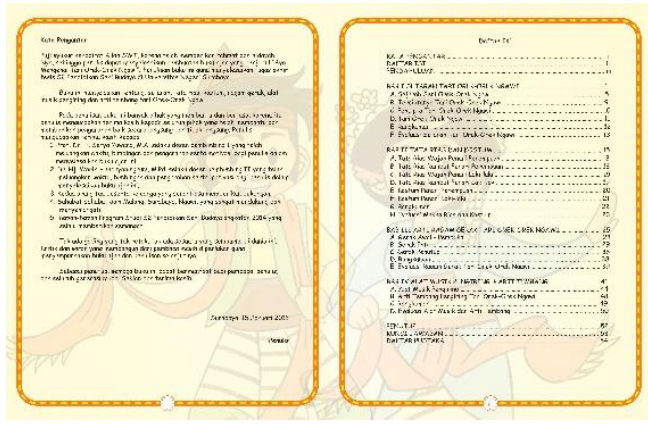

Gambar 3 lembar kata pengantar dan daftar isi

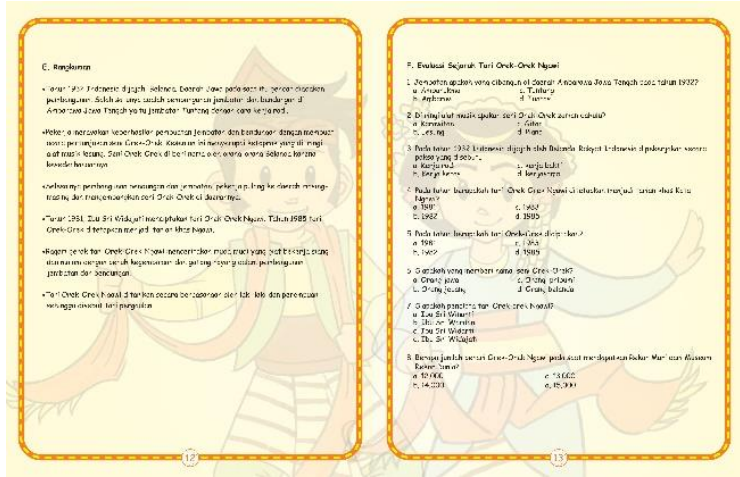

Gambar 5 rangkuman dan soal ujian

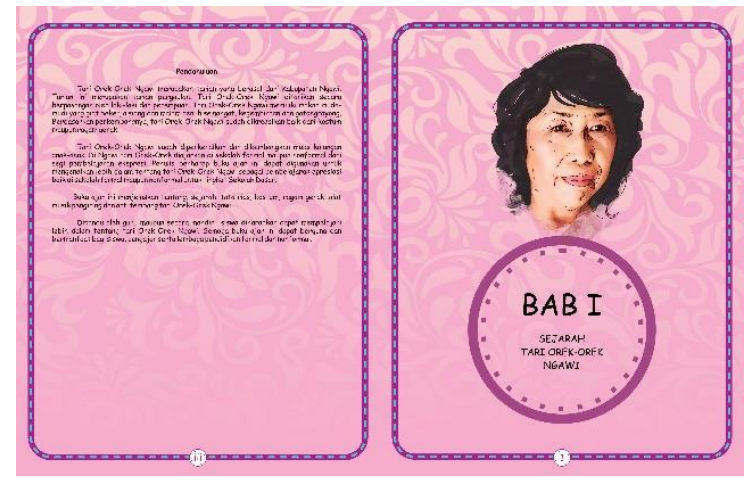

Gambar 4 pendahuluan dan judul bab

5. Tipografi isi buku

Jenis tulisan yang digunanakan didalam penjelasan materi yang mendukung gambar atau ilustrasi pop up adalah comic Sans MS. Huruf sederhana dan mudah sekali dibaca. Ukuran huruf seimbang dengan ukuran ilustrasi pop up sehingga saling menunjang untuk mudah dipahami. Penjelasan materi dominan pada ilustrasi dan dijelaskan dengan kata-kata namun tidak terlalu banyak dibanding dengan ilustrasinya.

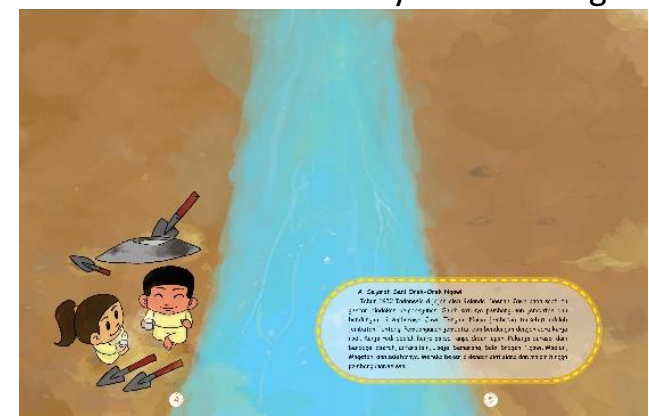

Gambar 6 contoh tipografi dalam pop up

6. Ilustrasi isi

Ilustrasi pada buku pop up ini di terapkan pada penjelasan isi materi. Gambar yang digunanan disesuikan dengan isian materi. Gambar-gambar tersebut mempermudah serta membuat kesan menarik karena ilstrasi gambar berkaitan dengan penjelasan. variasi ilustrai pada setiap bab juga memberikan kesan dinamis dan tidak membosankan, justru membuat semakin penasara untuk melihat setiap bab dengan materi yang berbeda. 

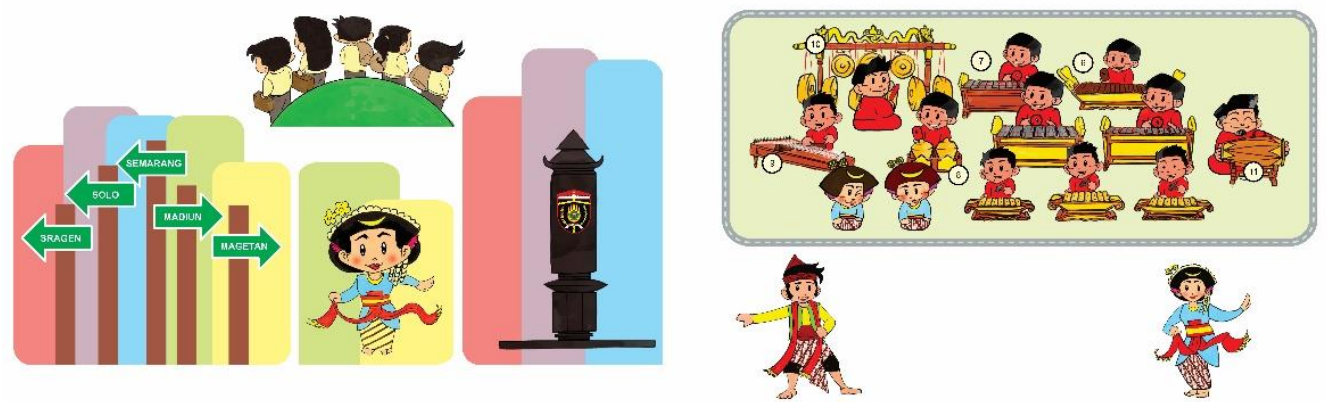

Gambar 7 contoh ilistrasi sebelum diterapkan

\section{Tahap III Develop (Pengembangan)}

Setelah mengetahui tingkat kelayakan Draf I. hasil penilaian, dimasukkan, dan saran dari tim validator I merupakan dasar untuk merevisi Draf I. kegiatan ini merupakan kegiatan Revisi I. Buku ajar yang telah direvisi, disampaikan kembali ke tim validator I sampai mendapat persetujuan. Media pembelajaran yang telah divalidasi, memiliki nilai layak dengan interval presentase dalam kategori baik. Dengan demikian buku ajar Pop Up Tari Orek-Orek Ngawi dapat diterapkan di SD terutama di ekstrakulikuler dan di sanggar.

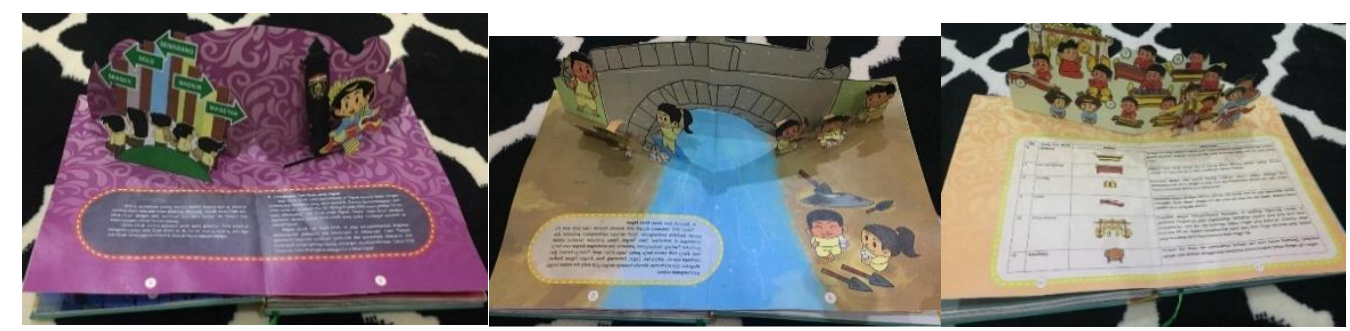

Gambar 8 Pop up Tari Orek-Orek Ngawi yang sudah di jadi

\section{Simpulan}

Pengembanagn buku ajar Pop Up Tari Orek-Orek Ngawi penting dilakukan untuk menambah referensi materi mengenai Tari Orek-Orek Ngawi yang hanya ada satu buku saja sebelumnya. Buku ajar dalam bentuk Pop Up tepat diberikan untuk anak Usia Sekolah dasar karena sesui dengan metode pembelajaran konstruktivistik yang dibutuhkan oleh mereka. Proses pembuatan buku Pop Up Tari Orek-Orek Ngawi dengan metode pengembangan four D yang disederhanakan menjadi three D yaitu, Define, Design dan Develop (pendefinisian, perancangan, dan pengembangan) berhasil menciptakan buku yang menarik dan interaktif. Dalam perancanagan tampilan buku pop up Tari Orek-Orek Ngawi sudah sesuai dengan standar kelayakan kegrafikaan dari BSNP artau Badan Standarisasi Nasional Pendidikan yang mencakup kelayakan ukuran buku, kulit buku, tipografi kulit buku, isi atau materi, tipografi isi dan ilustrasi buku. Buku ajar berbentuk Pop Up ini membantu siswa dapat dengan mudah mempelajari materi dengan cara menyenagkan dan mngkonstruksi pengetahuannya sendiri pengalaman membacanya. 


\section{Daftar Pustaka}

"Peraturan Menteri Pendidikan Nasional Republik Indonesia Tahun 2007 Tentang Standar Kualifikasi Penyusunan Buku Ajar." Badan Standar Nasional Pendidikan, 2007.

Elvinawati, Elvinawati. "Optimalisasi Pembelajaran Kimia Pemisahan Melalui Penerapan Pendekatan Konstruktivisme Dan Model Peta Konsep." EXACTA, vol. 9, no. 1, pp. 23-28, http://repository.unib.ac.id/503/.

Hanifah, Tisna Umi. "Pemanfaatan Media Pop-up Book Berbasis Tematik Untuk Meningkatkan Kecerdasan Verbal-Linguistik Anak Usia 4-5 Tahun (Studi Eksperimen Di Tk Negeri Pembina Bulu Temanggung)." BELIA: Early Childhood Education Papers, vol. 3, no. 2, 2014, https://journal.unnes.ac.id/sju/index.php/belia/article/view/3727.

Muqodas, Idat. "Mengembangkan Kreativitas Siswa Sekolah Dasar." Metodik Didaktik: Jurnal Pendidikan Ke-SD-an, vol. 9, no. 2, 2015, pp. 25-33, https://ejournal.upi.edu/index.php/MetodikDidaktik/article/view/3250.

Muslich, Masnur. Melaksanakan Ptk Penelitian Tindakan Kelas Itu Mudah. PT. Bumi Aksara, 2010.

Nurmawati et al. "Pembelajaran Yang Berorientasi Pada Konstruktivistik Untuk Meningkatkan Pemahaman Konsep Nilai Tempat Bagi Siswa Kelas lii Sd Negeri Kutoharjo li Rembang." Universitas Terbuka, 2000. http://repository.ut.ac.id/3271/http://repository.ut.ac.id/3271/.

Sukartiningsih, Wahyu. "Peningkatan Kemampuan Membaca Dan Menulis Permulaan Melalui Pembelajaran Konstruktivisme." Jurnal Pendidikan Dasar, vol. 6, no. 2, 2005, pp. 61-118.

Tim Proyek Pembinaan Jawa Timur. Tari Orek-Orek Ngawi. Provinsi Jawa Timur, 1994.

Trianto. Mengembangkan Model Pembelajaran Tematik. Prestasi Pustakaraya, 2010. 